\title{
Pengukuran Kinerja Manajemen Rantai Pasokan dengan SCOR Model 9.0 (Studi Kasus di PT Indocement Tunggal Prakarsa Tbk)
}

\author{
Anas Mutakin \\ Alumni Departemen Manajemen, Fakultas Ekonomi dan Manajemen \\ Institut Pertanian Bogor \\ Musa Hubeis \\ Departemen Manajemen, Fakultas Ekonomi dan Manajemen \\ Institut Pertanian Bogor \\ Email: hubeis.musa@yahoo.com
}

\begin{abstract}
The objectives of this research were (1) Assess the supply chain structure of cement products in PT Indocement Induk Prakarsa (ITP) Tbk; (2) Conduct performance measurement of supply chain management (SCM) for cement products in PT ITP Tbk approach Supply Chain Operations Reference (SCOR) model version 9.0; (3) Provide alternatives solution to the problem after the measurement is known along with suggestions of measurement and analysis activities of SCM at PT ITP Tbk. Calculation of performance metrics level 1 is the perfect order fulfillment (POF) 82.43\%, order fulfillment cycle time (OFCT) 2 days, the cost of good sold (COGS) 53.84\% and cash-tocash cycle time (CTCCT) 53 days. Opportunity value that is calculated using the lost opportunity measure (LOM) is a POF registration COGS $R p$ 552,146,310,636 and $R p$ 127,956,658,590. The mapping level 2 shows PT ITP Tbk have performance lowest deliver process, because the expedition and transportation of cement is less effective and efficient in sending customer orders. Mapping level 3 shows in detail the process of delivering PT ITP Tbk, so it can answer why deliver a low performance. From the results of the overall SCM performance PT ITP Tbk good enough, but needs to be improved on the expedition and the distribution of transportation to reach the target business objectives set PT ITP Tbk, which is improving customer service and increase profits.

Keywords: Supply Chain Management, SCOR Model, Performance, Measurement.
\end{abstract}

\section{Pendahuluan}

Pada era globalisasi ini, zaman sudah hiperkompetitif. Persaingan yang terjadi bukan sekedar "pertandingan" biasa, tetapi sudah mencapai pemberian nilai tambah pada produk dan jasa. Nilai strategi-strategi untuk menghadapi berbagai tantangan bisnis sangat diperlukan. Tren penjualan produk semen yang terus meningkat (Gambar 1) telah mengharuskan para manajer perusahaan merancang atau membangun sebuah rantai yang terdiri dari para pemasok, dengan memusatkan perhatian memaksimalkan nilai pelanggan. Dengan tingginya persaingan bisnis di berbagai bidang industri, khususnya industri semen, maka peningkatan daya saing perusahaan dalam bentuk efektifitas dan efisiensi produktivitas menjadi suatu hal 
terpenting, mutu produk dan pelayanan juga merupakan faktor utama yang mempengaruhi kepuasan pelanggan guna kelangsungan hidup perusahaan.

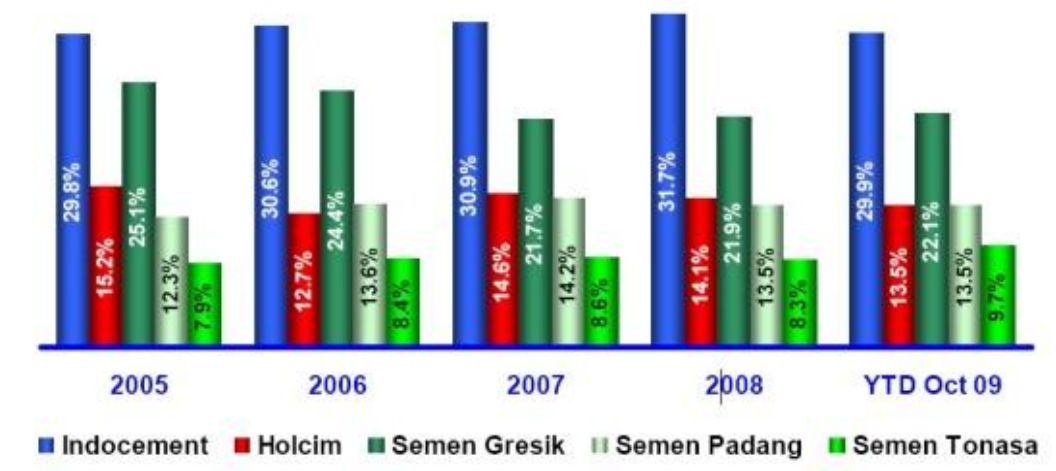

Gambar 1. Grafik Pangsa Pasar Semen di Indonesia (PT ITP Tbk, 2009ª)

Peningkatan efisiensi, salah satunya dapat dilakukan dengan integrasi kegiatan rantai pa-sok perusahaan, agar tidak terjadi kesulitan dalam proses perencanaan operasional rantai pasok. Konsep manajemen rantai pasok (Supply Chain Management atau SCM) mampu mengintegrasikan pengelolaan berbagai fungsi manajemen dalam suatu hubungan antar-organisasi membentuk satu sistem yang terpadu dan saling mendukung. Kunci bagi SCM efektif adalah menjadikan para pemasok sebagai "mitra" dalam strategi perusahaan untuk memenuhi pasar yang selalu berubah (Heizer dan Render, 2005). Teori dan praktik pada manajemen rantai pasokan telah banyak diterapkan pada perusahaan-perusahaan. Penerapan SCM yang telah ada, ternyata belum mencapai keefisienan dan keefektifan mengelola dan menjaga pemasok, agar tetap loyal terhadap perusahaan.

Pemasok-pemasok yang dipilih perusahaan yang tidak dikelola dengan baik memungkinkan para pemasok terlambat dalam pengadaan bahan baku bagi perusahaan, karena dapat menurunkan kinerja para pemasok dan tidak terjadinya transparansi harga tawar menawar antara pemasok dengan perusahaan. Penerapan SCM mengikuti konsep yang benar dapat memberikan dampak peningkatan keunggulan kompetitif terhadap produk maupun pada sistem rantai pasok yang dibangun pada perusahaan.

Salah satu perusahaan yang telah menerapkan konsep SCM adalah PT Indocement Tunggal Prakarsa Tbk (PT ITP Tbk). PT ITP Tbk bergerak di bidang industri semen memiliki berbagai pemasok persediaan bahan baku yang hampir keseluruhan proses produksinya tidak terlepas oleh sistem rantai pasok.

Penilaian kinerja manajemen rantai pasok antara pemasok, perusahaan dan pelanggan yang baik dapat diukur dengan salah satu model pengukuran kinerja SCM, yaitu model Supply Chain Operations Reference (SCOR), suatu model yang dirancang oleh Supply-Chain Council (SCC). Dalam hal ini terdapat beberapa versi pada SCOR. Saat ini SCC telah mengeluarkan model SCOR versi 9.0 (www. supply-chain.org, 2009). Model SCOR adalah salah satu model operasi rantai pasok, yang pada dasarnya merupakan model berdasarkan proses yang mengintegrasikan tiga (3) unsur utama dalam manajemen, yaitu Business Process Reengineering (BPR), benchmarking dan Best Practice Analysis (BPA) kedalam kerangka lintas fungsi rantai pasok. SCOR 
membagi proses-proses rantai pasok menjadi lima (5) proses inti, yaitu plan, source, make, deliver dan return. SCOR memiliki tiga(3) level proses dari umum hingga ke detil (Bol-stroff and Rosenbeum, 2003).

Penggunaan model SCOR dalam merancang sistem pengukuran kinerja rantai pasok berdasarkan proses, membuat perusahaan mampu mengevaluasi kinerja rantai pasok secara holistik untuk melakukan monitoring dan pengendalian, mengkomunikasikan tujuan organisasi ke fungsi-fungsi pada rantai pasok dan mengetahui dimana posisi suatu organisasi relatif terhadap pesaing, serta menentukan arah perbaikan bagi penciptaan keunggulan bersaing.

Perumusan masalah dalam penelitian ini adalah:

1. Bagaimana struktur rantai pasokan produk semen PT ITP Tbk ?

2. Bagaimana pengukuran kinerja terhadap manajemen rantai pasok di PT ITP Tbk dengan model SCOR versi 9.0 ?

3. Alternatif-alternatif solusi apakah yang ditemui dari masalah-masalah rantai pasok setelah diketahui pengukuran kinerja manajemen rantai pasok di PT ITP Tbk ?

Berdasarkan perumusan masalah tersebut, maka tujuan penelitian ini sebagai berikut:

1. Mengkaji struktur rantai pasokan produk semen di PT ITP Tbk.

2. Melakukan pengukuran kinerja terhadap manajemen rantai pasok untuk produk semen di PT ITP Tbk dengan model SCOR versi 9.0.

3. Memberikan alternatif-alternatif pemecahan atas masalah setelah diketahui pengukuran beserta saran dari kegiatan pengukuran dan analisis terhadap manajemen rantai pasok di PT ITP Tbk.

\section{Metode Penelitian}

PT ITP Tbk akan tetap eksis bila memiliki keunggulan daya saing terhadap lawanlawan bisnis, dilihat dari segi biaya, persediaan bahan baku, ketepatan jumlah dan waktu pemenuhan pesanan. Dari keunggulan tersebut PT ITP Tbk telah membentuk sistem integrasi rantai pasokan/bermitra dengan para pemasok bahan baku.

PT ITP Tbk telah merumuskan strategi SCM yang sesuai dan membentuk suatu sistem rantai pasok yang berjalan. Sistem rantai pasok yang telah berjalan dapat diketahui benchmark kinerjanya. Dengan demikian, benchmark kinerja PT ITP Tbk yang telah ada diukur dengan model SCOR versi 9.0. Jika hasilnya sesuai dengan standar benchmark dari model SCOR 9.0, maka dikatakan perusahaan ter-sebut baik dalam menerapkan sistem rantai pasok. Jika belum, maka perusahaan perlu meninjau kembali strategi SCM yang telah ditetapkan.

Dari serangkaian pengukuran dengan model SCOR 9.0. diketahui masing-masing kinerja pemasok. Setelah diketahui kinerja pemasok, maka permasalahan yang ada/yang belum baik dievaluasi dan diberikan saran sebagai hasil pengukuran, serta analisis terhadap SCM. Secara sistematik kerangka pemikiran penelitian dapat disajikan pada Gambar 2. 
92 | Mutakin, Hubeis - Pengukuran Kinerja Manajemen Rantai Pasokan

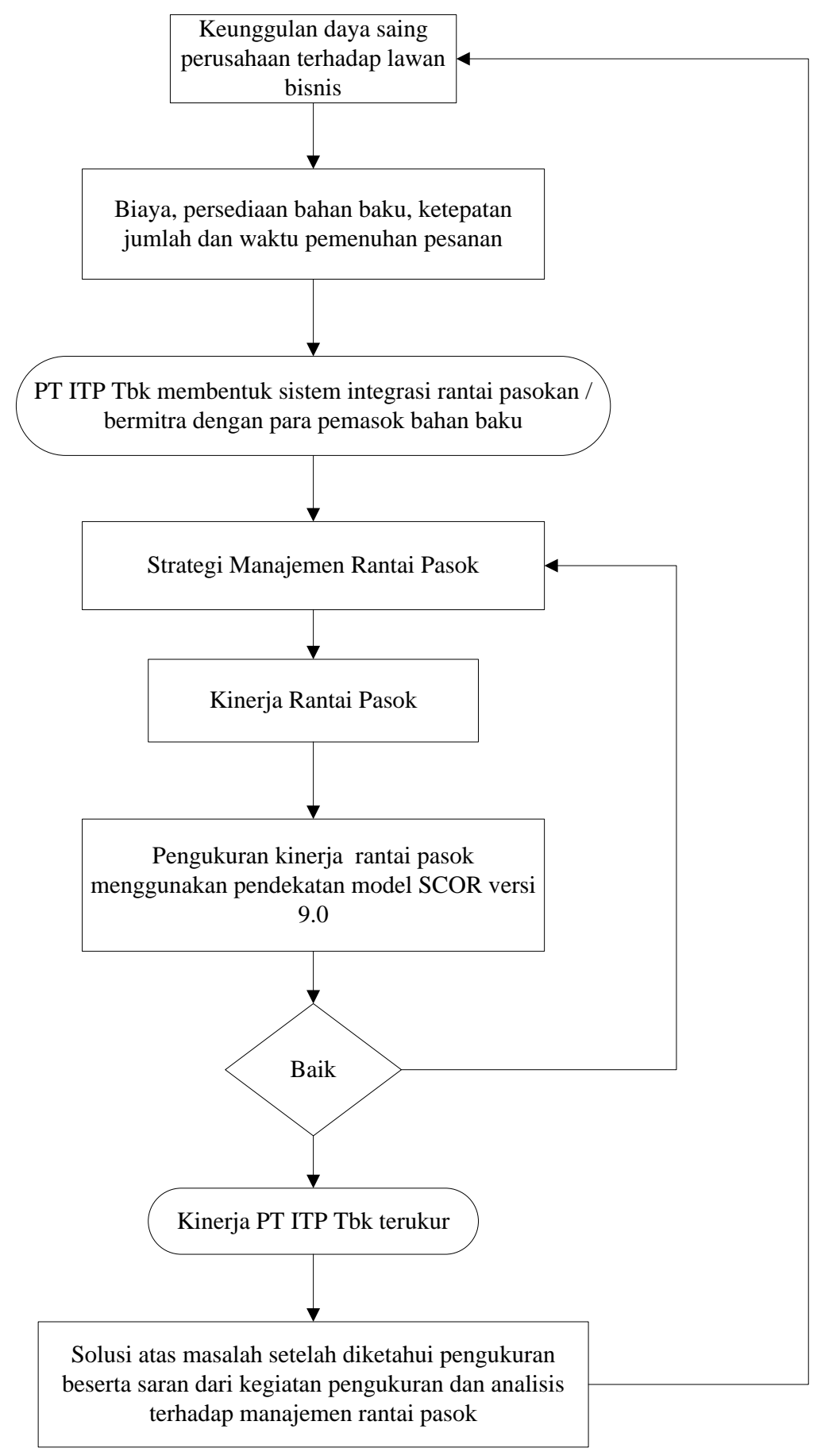

Gambar 2. Kerangka pemikiran penelitian

Penelitian dilaksanakan di PT ITP Tbk di Jalan Mayor Oking Jayaatmaja, Citeureup Bogor 16810, sebagai perusahaan penghasil semen terbesar di Indonesia yang telah menerapkan manajemen rantai pasok. Penelitian dilakukan pada bulan Desember 2009 hingga bulan Januari 2010.

Data penelitian adalah data primer dan sekunder yang bersifat kualitatif maupun kuantitatif. Data primer adalah data yang diperoleh langsung dengan cara observasi 
atau pengamatan, wawancara dan opini pakar. Data sekunder diperoleh dari studi pustaka, internet, jurnal dan dokumen-dokumen pendukung lainnya.

Data yang diperlukan meliputi:

1. Data tentang gambaran umum perusahaan, meliputi sejarah dan perkembangannya, struktur organisasi dan manajemen, serta bidang usaha yang merupakan data sekunder dari dokumen milik perusahaan.

2. Data tentang struktur rantai pasok perusahaan berupa data primer yang diperoleh secara langsung melalui wawancara dengan pihak perusahaan dan survei ke lapangan.

3. Data yang diperlukan untuk menganalisis kinerja SCM perusahaan adalah data trend produksi, neraca keuangan konsolidasi triwulan tahun 2009, daftar nama pemasok/prinsipal dan SCOR Quick Reference 9.0.

Pengolahan dan analisis data menggunakan pemodelan SCOR versi 9.0. Model SCOR merupakan model dari operasi rantai pasokan berdasarkan proses yang mengintegrasikan tiga unsur utama dalam manajemen, yaitu BPR, benchmarking dan BPA kedalam kerangka lintas fungsi supply chain. SCOR membagi proses-proses supply chain menjadi lima (5) proses inti, yaitu plan, source, make, deliver dan return. SCOR juga memiliki tiga (3) level proses dari umum hingga ke detil, yaitu:

1. Level satu (1) adalah level tertinggi yang memberikan definisi umum dari lima (5) proses inti.

2. Level kedua (2) dikatakan sebagai configuration level, dimana supply chain perusahaan dapat dikonfigurasi berdasarkan 30 proses inti, perusahaan dapat membentuk konfigurasi saat ini (as-in) maupun yang diinginkan (to-be).

3. Level ketiga (3) dinamakan proses unsur level yang mengandung definisi unsur proses, input metrik masing-masing unsur proses dan referensi.

Dalam metode SCOR terdapat atribut kinerja yang diukur, yaitu supply chain reliability, supply chain responsiveness, supply chain costs dan supply chain asset mana-gement. Parameter atribut menggunakan metrik kinerja berikut :

a. Perfect Order Fulfillment (POF)

POF adalah persentase dari pesanan yang terkirim lengkap dan pada waktunya sesuai dengan permintaan pelanggan dan barang yang dikirim tidak memiliki masalah mutu. Cara menentukan nilai POF adalah :

$$
\mathrm{POF}=\quad \frac{\text { Total pesanan-jumlah pesanan bermasalah }}{\text { Total pesanan }} \times 100 \%
$$

b. Order Fulfillment Cycle-Time (OFCT)

OFCT adalah jumlah waktu (hari) yang dibutuhkan sejak dari order diterima sampai produk diterima ditempat pelanggan. Besarnya nilai OFCT dapat diukur dari rataan jumlah hari yang dibutuhkan dalam pengiriman semen ke pelanggan, mulai dari pelanggan memesan barang hingga barang sampai ke tangan pelanggan.

c. Cost of Good Sold (COGS)

COGS adalah biaya langsung untuk material dan biaya upah yang dibutuhkan untuk membuat produk. COGS diartikan dengan harga pokok penjualan. Untuk menentukan nilai COGS adalah :

COGS = Inventori awal + pembelian selama periode - inventori akhir

d. Cash-to-cash cycle time (СTCCT) 
Metrik ini (Tabel 1) mengukur kecepatan supply chain mengubah persediaan menjadi uang. Semakin pendek waktu yang dibutuhkan, maka semakin bagus supply chain. Perusahaan baik memiliki siklus cash-to-cash pendek. Tiga (3) komponen dalam perhitungan CTCCT adalah :

Satu, rataan account receivable (hari) merupakan ukuran seberapa ce-pat pelanggan membayar barang yang sudah diterima; Dua, rataan account payable (hari) mengatur kecepatan perusahaan membayar ke pemasok untuk material/ komponen yang sudah diterima; Ketiga, rataan persediaan (dalam hari, yaitu inventory days of supply). Dengan ketiga (3) komponen tersebut, CTCCT dihitung berikut :

CTCCT = inventory days of supply + average days of account recivable - average days of account payable.

Metrik ini digunakan untuk mengukur kesehatan finansial suatu supply chain (Tabel 1). Untuk memperpendek CTCCT, perusahaan dapat melakukan salah satu (1) atau kombinasi dari tiga (3) cara berikut, yaitu (1) menurunkan tingkat persediaan; (2) melakukan negosiasi term pembayaran ke pemasok; dan (3) melakukan negosiasi dengan pelanggan supaya lebih cepat membayar. CTCCT yang mengintegrasikan siklus di tiga (3) fungsi, berupa pengadaan (purchasing), produksi (manufacturing) dan penjualan/distribusi (sales and distribution).

Tabel 1. Metrik Supply Chain Beserta Satuannya

\begin{tabular}{llcc}
\multicolumn{1}{c}{ Atribut Kinerja } & Metrik & Data Aktual & Data Benchmark \\
\hline Supply chain reliability & POF & $\%$ & $\%$ \\
Supply chain responsiveness & OFCT & Hari & Hari \\
Supply chain costs & COGS & $\%$ & $\%$ \\
Supply chain asset management & CTCCT & Hari & Hari \\
\hline
\end{tabular}

Sumber : Bolstroff and Rosenbeum, 2003.

Gap analysis digunakan pada saat melakukan analisis level 1, yaitu untuk menghitung besarnya peningkatan pendapatan (value of improvement atau opportunity) apabila target yang ditetapkan untuk setiap metrik dapat tercapai. Besarnya opportunity dihitung dengan salah satu dari tiga (3) metode (Bolstorff and Rosenbeum, 2003) berikut:

1) The Lost Opportunity Measure (LOM)

Perhitungan dilakukan menurut besarnya pendapatan yang tidak dapat diraih (lost) sebelum order-entry, karena barang tidak tersedia.

2) The Cancelled Order Measure (COM)

Perhitungan dilakukan menurut besarnya pendapatan yang tidak dapat diraih (lost) setelah order-entry yang disebabkan oleh pembatalan pesanan, karena kinerja pengiriman kurang baik.

3) The Market Share Measure (MSM)

Metode ini menghitung perkiraan peningkatan pendapatan sebagai dampak dari terciptanya competitive advantage berdasarkan kategori customer-facing metrics. 


\section{Hasil Penelitian}

III. 1. Pemetaan Level 1

PT ITP Tbk dalam menjalankan operasi produksinya menerapkan rantai pasok yang melibatkan berbagai tahapan-tahapan mata rantai dari pemasok hingga ke pelanggan. Rantai pasok PT ITP Tbk mempunyai dua (2) jalur pasokan (Gambar 3 dan 4). Jalur pasokan pertama disebut proses pesanan barang jadi (semen) pada Gambar 3 dan jalur pasokan kedua disebut proses fisik pada Gambar 4.

Permintaan akan semen di PT ITP Tbk pada jalur pertama (1) melalui dua (2) distributor. Toko pelanggan memesan semen kepada City Distributor (CD), dimana setiap CD mempunyai wilayah pemasaran dan toko pelanggan masing-masing, serta bertanggung-jawab untuk mencari pelanggan baru. Fungsi lain CD adalah memelihara wilayah pemasarannya dari serangan pesaing dan membuat program promosi untuk menarik pelanggan baru.

Setelah pesanan dari toko terkumpul semua, data pesanan di proses melalui sistem WOMS (Web Order Management System) dan selanjutnya dikirim ke server Main Distributor (MD) untuk dilakukan pengolahan data. Dalam pengolahan data ini termasuk juga melakukan seleksi terhadap pelanggan yang masih mempunyai piutang, bila masih mempunyai piutang dan sudah jatuh tempo belum melakukan pembayaran, maka oleh sistem secara otomatis pesanannya tidak akan di proses. Hasil pengolahan data dari WOMS diunggah ke komputer pusat PT ITP Tbk. Oleh petugas PT ITP Tbk, pesanan dipilah berdasarkan wilayah pemasaran untuk menentukan dispatch origin, yaitu pusat distribusi, baik plant atau warehouse. Tujuan dari penentuan dispatch origin untuk efisiensi ongkos angkut truk yang disewa oleh PT ITP Tbk.

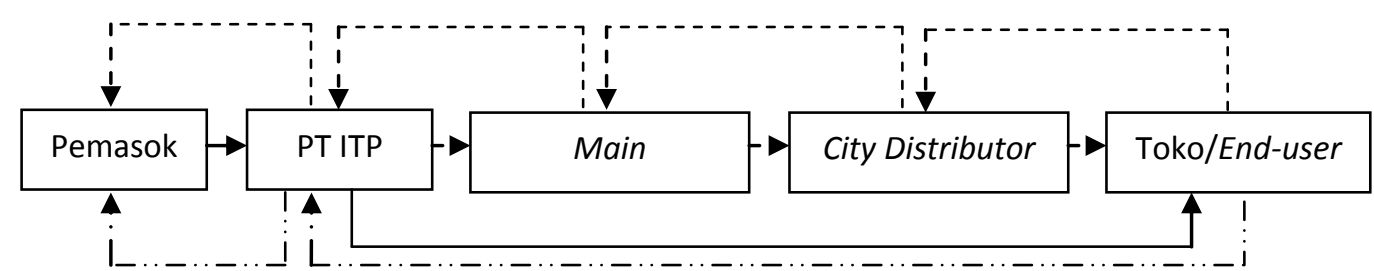

Gambar 3. Rantai Pasok Jalur Pertama PT ITP Tbk (PT ITP, 2009ª)

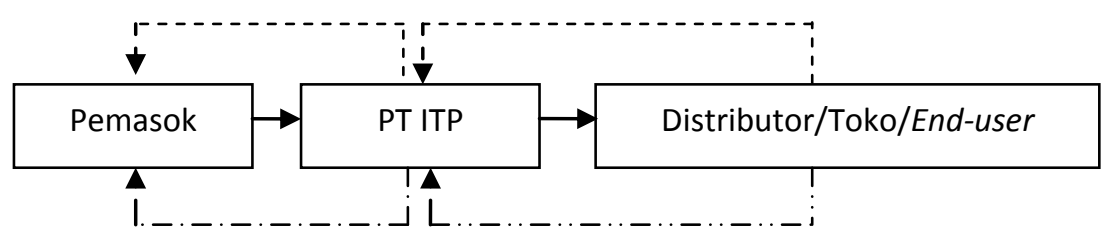

Gambar 3. Rantai Pasok Jalur Kedua PT ITP Tbk (PT ITP, 2009ª)

Keterangan :

$\longrightarrow$ Aliran material

- Aliran Informasi dan data

$\rightarrow$ Aliran uang

Dispatch origin mengunduh DO (Delivery Operation) dan mencetaknya dari perusahaan. Dispatch origin menentukan waktu pengiriman sesuai dengan keinginan pelanggan, yaitu harapan pengiriman yang dicantumkan di data DO Proses pesanan. Selanjutnya PT ITP Tbk langsung mengirimkan pesanan ke tempat tujuan masing- 
masing. Pembelian semen melalui PT ITP Tbk, minimal transaksi pembelian adalah 1 DO (1 DO = 160 sak semen = 8 ton). Rantai pasok jalur kedua disajikan pada Gambar 4.

\section{2. Metrik Kinerja SCOR Level 1}

Rantai pasok semen Tiga Roda akan diukur dengan metrik kinerja level 1 (satu), yaitu kinerja penyampaian PT ITP Tbk. dalam menyampaikan semen kepada pelanggan (toko). Bolstorff (2003) menjelaskan bahwa analisis level 1 (satu) dimulai dengan mendefinisikan tujuan bisnis perusahaan. Hal ini dilakukan agar evaluasi kinerja rantai pasok yang akan dilakukan sejalan dengan strategi perusahaan dan fokus pada tujuan utama yang ingin dicapainya.

Berdasarkan hasil wawancara dengan bagian logistic division PT ITP Tbk, disebutkan bahwa tujuan bisnis PT ITP Tbk didefinisikan sebagai berikut :

1. Memberikan tingkat pelayanan terbaik.

2. Meningkatkan keuntungan perusahaan.

Tujuan pertama dicapai dengan meng-analisis nilai dari tiga (3) indikator berikut :

a. Delivery performance.

b. Responsiveness to customer demand.

c. Flexibility to demand changes.

Tujuan kedua dapat dicapai dengan menganalisis nilai dari dua indikator di bawah ini :

a. Supply chain cost.

b. Asset management efficiency.

Setelah mengetahui tujuan bisnis di atas langkah selanjutnya mengukur metrikmetrik pada SCOR menurut tujuan bisnis tersebut. Berdasarkan perhitungan, metrikmetrik yang diberikan oleh SCOR dapat dilihat pada kolom data aktual pada Tabel 2. Untuk tujuan bisnis pertama (1), data yang tersedia adalah POF dan OFCT. Sementara untuk tujuan kedua (2), adalah COGS dan CTCCT.

Setelah mendapatkan data aktual dan mengkalkulasi berdasarkan keempat (4) metrik tersebut, langkah selanjutnya menentukan posisi aktual dan menetapkan kinerja target untuk masing-masing metrik berdasarkan data benchmark.

Tabel 2. Metrik SCOR Model Level 1

\begin{tabular}{llcccc}
\hline Performance Atribute & \multicolumn{1}{c}{ Level 1 Metric } & $\begin{array}{c}\text { Actual } \\
\text { Data (a) }\end{array}$ & $\begin{array}{c}\text { Superior } \\
\text { (b) }\end{array}$ & $\begin{array}{c}\text { Advantage } \\
\text { (c) }\end{array}$ & Parity (d) \\
\hline $\begin{array}{l}\text { Supply Chain } \\
\begin{array}{l}\text { Reliability } \\
\text { Supply Chain }\end{array}\end{array}$ & POF (\%) & 82,43 & 99 & 90,8 & 80 \\
$\begin{array}{l}\text { Responsiveness } \\
\text { Supply Chain Costs }\end{array}$ & $\begin{array}{l}\text { Supply Chain } \\
\text { Management Cost }\end{array}$ & N/A & N/A & N/A & N/A \\
$\begin{array}{l}\text { COGS (\%) } \\
\text { CTCCT (hari) }\end{array}$ & 53,84 & 27,3 & 50 & 64,3 \\
$\begin{array}{l}\text { Manply Chain Asset } \\
\text { Return on Supply }\end{array}$ & 53 & 25 & 41 & 62,5 \\
& Chain Fixed Assets & N/A & N/A & N/A & N/A \\
\hline
\end{tabular}


Data benchmark diperoleh dari Global Supply Chain Benchmark tahun 2010 untuk industri semen yang dikeluarkan oleh SCC, sebuah lembaga non-profit yang independen di Amerika Serikat. Global Supply Chain Benchmark 2010 merupakan hasil kerjasama antara SCC dan APQC (American Productivity and Quality Center)/ http://www.apqc org, sebuah lembaga non-profit yang ber-gerak dalam bidang riset tentang bench-marking untuk perusahaan-perusahaan da-lam industri tertentu.

Data benchmark ini digunakan untuk menentukan kinerja target, memberikan gambaran mengenai besarnya gap antara kinerja perusahaan dengan kinerja perusahaan yang menjadi acuan dalam data benchmark dan tren kinerja dari tahun ke tahun, serta membantu dalam mengarahkan pengembangan rantai pasok. Data aktual dan benchmark dari industri sejenis secara global yang terdiri dari tiga kategori untuk mengetahui posisi kinerja PT ITP pada Tabel 2.

Berdasarkan Tabel 2 terlihat bahwa tujuan bisnis memberikan tingkatan layanan terbaik, metrik POF pada data aktual PT ITP Tabk berada di antara parity dan advantage. Sedangkan metrik OFCT berada di antara advantage dan superior. Untuk itu. PT ITP Tbk harus menetapkan kinerja target untuk POF dan OFCT pada posisi superior karena keduanya sejalan dengan tujuan bisnis yang utama, yaitu memberikan tingkat layanan terbaik. Metrik untuk tujuan bisnis kedua (2), meningkatkan keuntungan perusahaan, yaitu COGS pada data aktual PT ITP Tbk berada di antara parity dan advantage. Sedangkan CTCCT pada data aktual PT ITP Tbk berada di antara parity dan advantage.

Data aktual COGS dan CTCCT tidak dapat diperoleh dalam satu angka yang pasti, karena data bersifat rahasia. Dalam mengolah data COGS dan CTCCT, data tersebut diperoleh dari neraca konsolidasi triwulan PT ITP Tbk, per 30 September 2009. Dengan asumsi perusahaan yang menetapkan pengurangan biaya pada produksi dan operasi perusahaan, COGS berada pada posisi antara parity dan advantage, serta mengacu pada Tabel 2 terlihat bahwa target COGS yang ingin dicapai berada pada posisi advantage.

Dalam SCOR Model, tidak disarankan terdapat lebih dari satu tujuan bisnis dengan kinerja target pada posisi superior. Lingkup proyek pengembangan rantai pasok yang kompleks menghendaki adanya pembatasan kinerja target pada posisi superior, agar usaha perbaikan yang dilakukan hanya pada satu (1) tujuan bisnis. Oleh karena itu, kinerja target untuk COGS ditetapkan pada posisi advantage. Terakhir, kinerja target untuk CTCCT, yaitu pada posisi parity, dikarenakan dalam SCOR tidak memungkinkan lebih dari satu (1) target pada posisi advantage.

Setelah menetapkan kinerja target, langkah selanjutnya adalah melakukan gap analysis yang bertujuan menghitung besarnya perbedaan antara kondisi aktual dengan yang ditargetkan. Besarnya perbedaan tersebut diterjemahkan dalam besarnya peningkatan pendapatan, apabila kinerja ditingkatkan sampai mencapai target (Bolstorff and Rosenbeum, 2003).

Besarnya perbedaan berdasarkan gap analysis disajikan dalam Tabel 3, dimana kolom opportunity diisi dengan besarnya peningkatan pendapatan, bila kinerja untuk metrik-metrik tersebut ditingkatkan sampai pada posisi yang ditargetkan. Untuk menghitung opportunity, diperlukan data nilai total pendapatan dan persentase laba kotor yang dihasilkan oleh produk semen (Bolstorff, 2003). Namun karena data keuangan 
bersifat rahasia dan penelitian dilakukan pada bulan Desember, dimana perusahaan belum melakukan tutup buku, maka besarnya opportunity dihitung menggunakan beberapa angka pendekatan.

Pertama (1), laba kotor PT ITP Tbk di-ambil dari neraca konsolidasi triwulan per 30 September 2009, karena perusahaan melakukan laporan keuangan setiap triwulan tahun berjalan. Berdasarkan laporan keuangan PT ITP Tbk per 30 September 2009, diketahui besarnya laba kotor 46,16\%. Kedua (2), total pendapatan dihitung berdasarkan penjualan dari total produksi semen selama triwulan September 2009.

Dalam hal ini, terdapat beberapa metode dalam SCOR Model yang dapat digunakan untuk menghitung besarnya opportunity untuk POF. Salah satu metode yang digunakan dalam penelitian ini adalah LOM (Bolstroff, 2003). Dengan metode ini dapat diketahui besarnya kesempatan yang hilang untuk memperoleh pendapatan tertentu berbasis kinerja POF dan COGS saat ini. Cara menghitung opportunity untuk metrik POF dan COGS dijelaskan pada Tabel 4-5.

Besarnya opportunity untuk metrik OFCT dalam mencapai target sejalan dengan opportunity yang berasal dari POF. Apabila OFCT makin rendah, artinya waktu tunggu makin pendek, maka otomatis membuat nilai POF semakin tinggi dan berdampak pada peningkatan pendapatan (Bolstroff, 2003). Opportunity untuk metrik COGS diperoleh dengan menghitung besarnya penurunan COGS, bila target tercapai. Penurunan tersebut secara langsung menandakan peningkatan dalam laba kotor atau laba operasi seperti terlihat pada Tabel 5.

Terakhir, perhitungan besarnya opportunity dari CTCCT diperlukan data besarnya biaya bunga per hari, tetapi karena perusahaan tidak berkenan memberikannya, maka besarnya nilai opportunity tidak dapat ditentukan.

Tabel 3.

\begin{tabular}{|c|c|c|c|c|c|c|c|}
\hline $\begin{array}{c}\text { Performance } \\
\text { Atribute }\end{array}$ & $\begin{array}{l}\text { Level } 1 \\
\text { Metric }\end{array}$ & $\begin{array}{l}\text { Actual } \\
\text { Data }\end{array}$ & Superior & Advantage & Parity & $\begin{array}{l}\text { Requirement } \\
\text { Gap }\end{array}$ & Opportunity \\
\hline $\begin{array}{l}\text { Supply Chain } \\
\text { Reliability }\end{array}$ & POF (\%) & 82,43 & 99 & 90,8 & 80 & 16,6 & Rp 552.146.310.636*) \\
\hline $\begin{array}{l}\text { Supply Chain } \\
\text { Responsiveness }\end{array}$ & $\begin{array}{l}\text { OFCT } \\
\text { (hari) }\end{array}$ & 2 & 1,6 & 4 & 7 & 2 & $\begin{array}{l}\text { Meningkatkan kehandalan } \\
\text { pasokan/pengiriman }\end{array}$ \\
\hline Supply Chain Costs & $\mathrm{SCM}$ & $\mathrm{N} / \mathrm{A}$ & $\mathrm{N} / \mathrm{A}$ & N/A & N/A & N/A & N/A \\
\hline & COGS (\%) & 53,84 & 27,3 & 50 & 64,3 & 3,8 & $\operatorname{Rp} 127.956 .658 .590 * *)$ \\
\hline \multirow[t]{2}{*}{$\begin{array}{l}\text { Supply Chain Asset } \\
\text { Management }\end{array}$} & $\begin{array}{l}\text { СТCСТ } \\
\text { (hari) }\end{array}$ & 53 & 25 & 41 & 62,5 & 9,5 & $\begin{array}{l}\text { Mengurangi beban bunga } \\
\text { dan opportunity cost }\end{array}$ \\
\hline & $\begin{array}{l}\text { Return on } \\
\text { Supply } \\
\text { Chain } \\
\text { Fixed } \\
\text { Assets }\end{array}$ & N/A & N/A & N/A & N/A & N/A & $N / A$ \\
\hline
\end{tabular}

Keterangan : N/A = not available

*) Lihat Tabel 4

Target Kinerja

**) Lihat Tabel 5 
Tabel 4. Tabel perhitungan opportunity untuk POF dengan LOM

\begin{tabular}{|c|c|}
\hline Komponen & Hasil Perhitungan \\
\hline Total pendapatan (Rp) & 7.218.814.234.817 \\
\hline POF aktual (\%) & 82,43 \\
\hline POF target (superior) ; \% & 99 \\
\hline Total pendapatan x ((100-POF aktual)/100) (a) ; Rp & 1.268.345.661.057 \\
\hline Total pendapatan x ((100-POF target)/100) (b) ; Rp & 72.188 .142 .348 \\
\hline Selisih (a) dan (b) ; Rp & 1.196.157.518.709 \\
\hline Laba kotor $(\%)$ & 46,16 \\
\hline Laba kotor x selisih (opportunity) ; Rp & 552.146 .310 .636 \\
\hline \multicolumn{2}{|l|}{ Tabel 5.} \\
\hline Komponen & Hasil Perhitungan \\
\hline Total pendapatan (Rp) & 7.218.814.234.817 \\
\hline COGS aktual (\%) & 53,84 \\
\hline COGS target (advantage) ; \% & 50 \\
\hline Total pendapatan x COGS aktual (a) ; Rp & 3.886.609.584.025 \\
\hline Total pendapatan x COGS target (b) ; Rp & 3.609.407.117.409 \\
\hline Selisih (a) dan (b) ; Rp & 277.202.466.616 \\
\hline Laba kotor (\%) & 46,16 \\
\hline Laba kotor x selisih (opportunity) ; Rp & 127.956 .658 .590 \\
\hline
\end{tabular}

\section{3. Pemetaan Level 2}

Pada pemetaan level 2 (dua : Gambar 5), setiap proses inti dalam SCOR ditampilkan lebih rinci dari tiga tipe proses SCOR, yaitu planning (perencanaan), excecution (pelaksanaan) dan enable (pengaturan antara perencanaan dan pelaksanaan). Peninjauan rantai pasok pada level 2 (dua) lebih detil dilakukan pada pengidentifikasian nilai metrik POF dan OFCT yang masih kurang baik. Sedangkan pengidentifikasian nilai metrik COGS dan CTCCT tidak perlu diukur, karena dengan menganalisis POF dan OFCT akan langsung memberikan dampak perbaikan pada nilai COGS dan CTCCT.

Dalam perhitungan POF dan OFCT, perlu diperhatikan ketepatan waktu (on time), ketepatan kuantits (in full) dan kelengkapan dokumen pendukung, serta kondisi barang (perfect condition). Apabila ada salah satu syarat tersebut di atas yang tidak terpenuhi, maka pelayanan yang diberikan PT ITP Tbk kurang baik. Berdasarkan data logistik tahun 2009, diketahui penyebab ketidaksempurnaan dalam pemenuhan pesanan disebabkan oleh pengiriman barang yang tidak tepat waktu (not in time).

Tabel 6. Nilai POF dan OFCT pada Proses Deliver, Make dan Source

\begin{tabular}{lcccc}
\hline & Metrik & Deliver & Make & Source \\
\hline POF (\%) & 80 & 99 & 95 \\
OFCT (hari) & 2 & $<1$ & 2 \\
\hline
\end{tabular}

Berdasarkan ketiga nilai tersebut beserta analisisnya, terlihat bahwa proses deliver memiliki kinerja paling rendah. Ketidaktepatan pengiriman yang dilakukan PT ITP Tbk secara keseluruhan dapat menghambat tujuan bisnis perusahaan, yaitu meningkatkan pelayanan pelanggan. Untuk mengetahui apa yang menyebabkan kinerja proses deliver menjadi rendah, maka dilakukan penelitian pada level 3 (tiga). 


\section{4. Pemetaan level 3}

Analisis pemetaan level 3 (tiga) dilakukan untuk melihat lebih detil proses deliver, karena memiliki kinerja paling rendah berdasarkan analisis level 2 (dua). Pemetaan level 3 (tiga) dilakukan atas semua aktivitas dalam proses deliver, sehingga diperoleh Gambar 6 konfigurasi saat ini (As-Is-Process). Gambar tersebut memperlihatkan pengelolaan pengiriman material (deliver) di PT ITP Tbk yang terdiri dari input (masukan), process elements (proses unsur) dan outputs (keluaran).

Penyebab pengiriman barang yang tidak tepat waktu dimulai dari hilir ke hulu dapat ditelusuri pada proses delivery, make dan source. Pada proses pengiriman, nilai POF $80 \%$. Angka ini diperoleh dari perkiraan atas berapa persen ketepatan pengiriman barang dalam hal kuantitas yang sesuai dengan dengan permintaan barang. Sedangkan nilai OFCT sekitar 2 (dua) hari. Angka disebut diperoleh dari rataan pengiriman barang sampai di pelanggan sesuai dengan harapan pengiriman pelanggan.

Pada proses make, nilai POF hampir $100 \%$. Angka tersebut diperoleh berdasarkan perkiraan atas berapa persen kebutuhan bagian produksi yang dapat dipenuhi oleh bagian penggudangan bahan baku untuk proses produksi. Hal ini didukung oleh lokasi penggudangan bahan baku yang satu lokasi dengan pabrik. Setiap pabrik PT ITP Tbk terdapat gudang bahan baku semen. Nilai OFCT sekitar 1 hari. Pada proses source, nilai POF sekitar 95\%. Angka tersebut diperoleh berdasarkan perkiraan atas berapa persen jumlah pesanan bahan baku dari PT ITP Tbk yang dapat dipenuhi oleh pemasok dengan baik berdasarkan ketiga syarat yang telah disebutkan tadi. Nilai OFCT sekitar 2 (dua) hari. Tabel 6 nilai POF dan OFCT pada proses deliver, make dan source. 


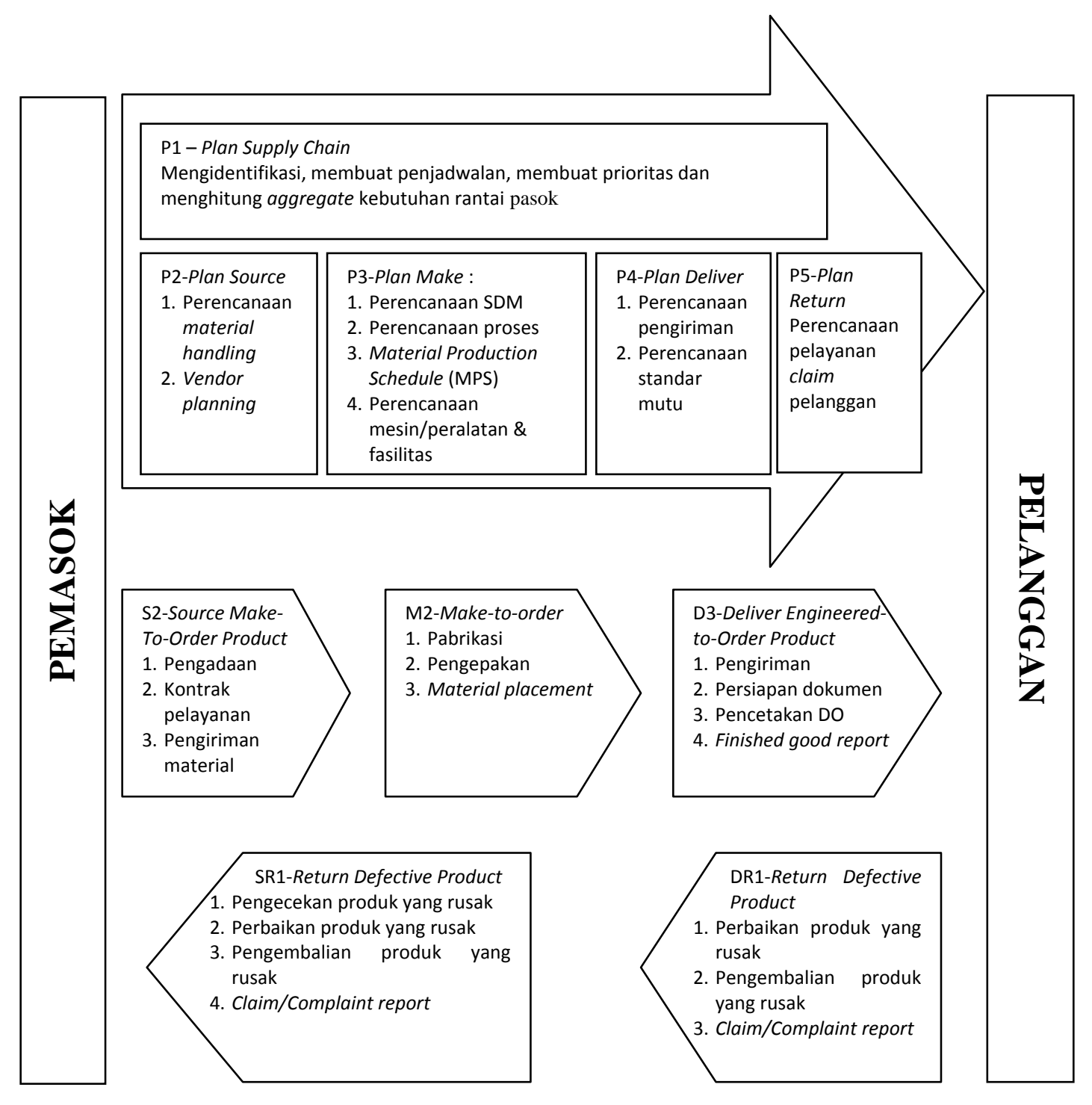

\section{Enable :}

1. Membuat dan mengelola aturan main tiap proses

2. Melakukan penilaian kinerja tiap proses

3. Mengelola data

4. Mengelola persediaan

5. Mengelola aset modal

6. Mengelola transportasi

7. Mengelola konfigurasi rantai pasok

8. Mengelola peraturan

9. Mengelola risiko proses pada rantai pasokan

10. Mengidentifikasi unsur proses

Gambar 4. Pemetaan Level 2 Rantai Pasok Produk Semen 


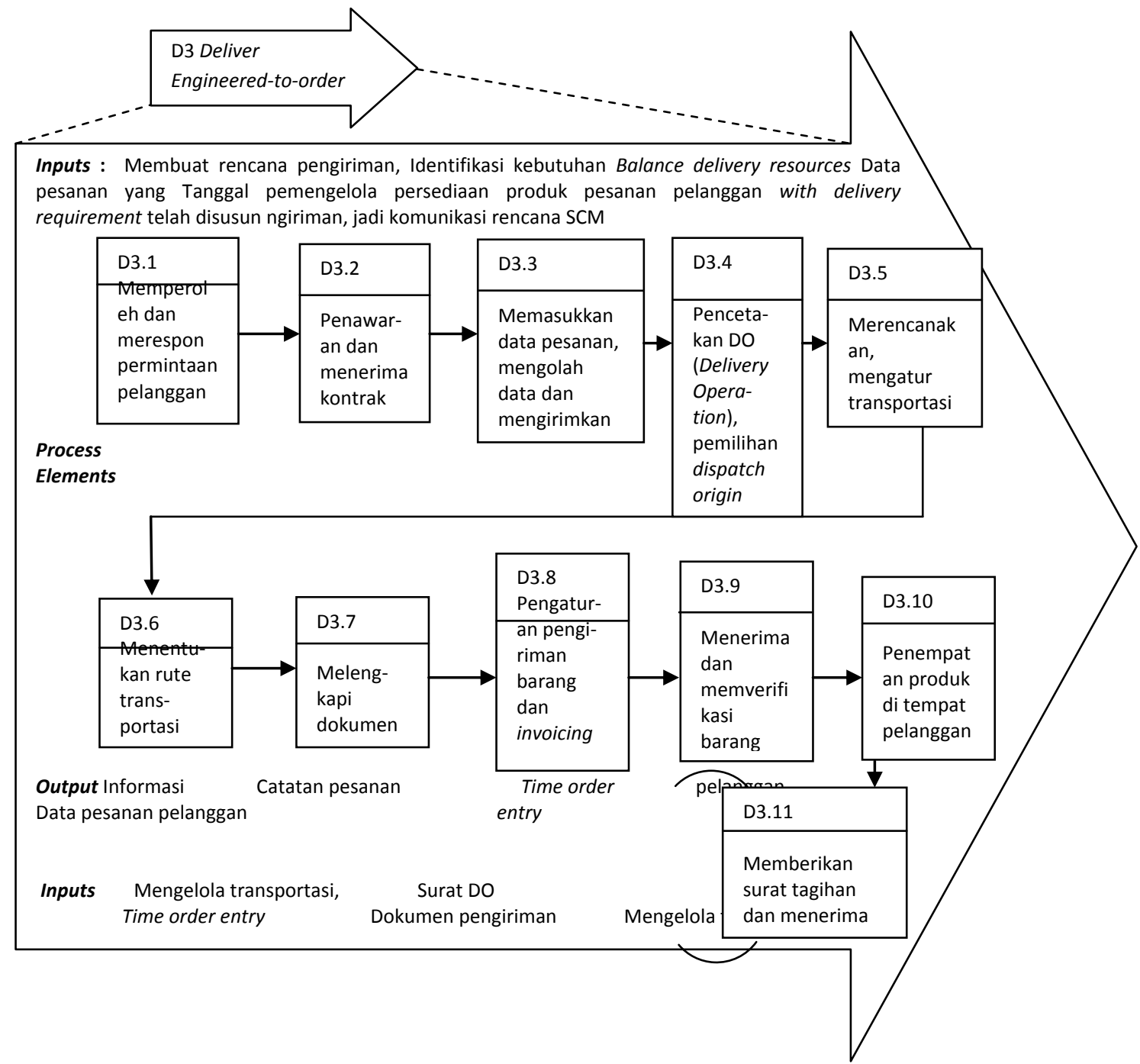

Gambar 5. Pemetaan Level 3 Rantai Pasok Produk Semen (As- Is-Process)

\section{KESIMPULAN}

PT ITP Tbk dalam menjalankan operasi produksinya mempunyai dua (2) jenis struktur rantai pasokan yang melibatkan berbagai tahapan-tahapan dari pemasok hingga pelanggan (end-user). Struktur rantai pasokan pertama (1) adalah struktur rantai pasokan proses order ba-rang jadi/semen. Struktur rantai pasok proses order barang jadi/semen terdapat aliran material dan informasi. Skema rantai pasok proses order barang jadi/semen yang terjadi aliran informasi diawali dari konsumen-CD-MDPT ITP Tbk-pemasok. Sedangkan aliran material pada rantai pasok proses order barang jadi/semen diawali dari pemasok-PT ITP Tbk-MD-CD- konsumen. Struktur rantai pasokan kedua (2) adalah struktur rantai pasok-an proses fisik yang terdapat pada aliran material dan informasi. Skema struktur tersebut diawali dari pemasok-PT ITP Tbk-distributor/toko/pelanggan. Sedangkan yang terjadi pada aliran informasi diawali dari distributor/toko/ pelanggan - PT ITP Tbk -pemasok.

Hasil yang diperoleh dari hasil pengukuran kinerja metrik : (1) level 1 adalah POF = $82,43 \%$, OFCT $=2$ hari, COGS $=53,84 \%$ dan CTCCT $=53$ hari. Dari hasil benchmark, nilai POF dan COGS belum mencapai target. Sedangkan nilai OFCT dan CTCCT PT ITP Tbk 
telah melewati target yang diterapkan. Dari penelitian gap analysis, diperoleh PT ITP Tbk mengalami banyak biaya yang hilang, karena ketidakefisienan dan ketidakefektifan SCM; (2) Pada level 2 (dua) ditelusuri lebih detil lagi dari level 1 (satu) dengan melakukan pe-metaan level 2 (dua), diperoleh hasil proses deliver semen memiliki kinerja paling rendah dan dilakukan analisis pada level 3 (tiga) guna memaparkan lebih detil lagi proses deliver dengan kinerja paling rendah. PT ITP telah menerapkan SCM dengan baik, yaitu menerapkan kelima (5) proses manajemen inti dalam SCM, sehingga seluruh unsur rantai pasok saling terintegrasi dan menghasilkan kinerja cukup baik, namun kurang memperhatikan proses pengiriman (bidang ekspedisi dan transportasi). Alternatif pemecahan atas masalah tersebut adalah PT ITP Tbk harus fokus dan konsisten dalam proses pengiriman untuk mencapai target-target metrik kinerja SCM untuk memberikan pelayanan terbaik kepada konsumen dan me-ningkatkan keuntungan perusahaan.

\section{DAFTAR PUSTAKA}

Bolstorff, P. and R. Rosenbeum. 2003. Supply Chain Excellence : A Handbook for Dramatic Improvement Using The SCOR Model. AMACOM, New York.

Heizer, J. dan B. Render. 2005. Manajemen Operasi (Terjemahan). Salemba Empat, Jakarta.

http://www.apqc.org. 2010. Global SCC Benchmark. the American Productivity and Quality Center, USA.

http://www.supply-chain.org. 2009. Supply chain operations reference model SCOR version 9.0.

PT ITP Tbk. 2009ª . Gambaran Umum PT ITP Tbk. PT Indocement Tunggal Prakarsa Tbk, Bogor.

. 2009 ${ }^{\mathrm{b}}$. Laporan pengiriman semen. Bagian Logistik PT ITP Tbk. PT Indocement Tunggal Prakarsa Tbk, Bogor. 